\title{
Metabolism of Clomipramine in a Japanese Psychiatric Population: Hydroxylation, Desmethylation, and Glucuronidation
}

Kazutaka Shimoda, M.D., Ph.D., Toshifumi Noguchi, M.D., Ph.D., Yuhi Ozeki, M.D., Sachiyo Morita, M.D., Morikazu Shibasaki, M.D., Toshiyuki Someya, M.D., and Saburo Takahashi, M.D., Ph.D.

We measured the concentrations of clomipramine and its metabolites, $\mathrm{N}$-desmethylclomipramine, 8-hydroxy-Ndesmethylclomipramine, 8-hydroxyclomipramine by highperformance liquid chromatography in 108 Japanese psychiatric patients receiving clomipramine hydrochloride $P O$. The concentrations of the glucuronide conjugates of 8-hydroxyclomipramine and 8-hydroxy-N-desmethylclomipramine were assayed via enzymatic hydrolysis. Although there were large interindividual variations of concentrations of parent, intermediate metabolic compounds, and glucuronide conjugates, significant positive correlations were observed between these drug concentrations and daily doses of clomipramine hydrochloride ( $\mathrm{mg} / \mathrm{kg}$ body weight). Although the metabolic ratios for desmethylation, hydroxylation, and glucuronidation that were calculated from steady-state drug concentrations varied substantially with 36-, 14-, and 28-fold interindividual variations, respectively, apparent poor desmethylators, poor hydroxylators, or poor glucuronidators were not found.

[Neuropsychopharmacology 12:323-333, 1995]
KEY WORDS: Tricyclic antidepressants: Clomipramine; Hydroxylation; Desmethylation; Glucuronidation

Interindividual differences in drug metabolism, which determine plasma levels or adverse drug effects, have been observed. In particular, the existence of poor metabolizers has been noted for various drugs, including debrisoquine, sparteine, mephenytoin, or desipramine (Jacqz et al. 1986). For example, plasma levels of

From the Department of Psychiatry (KM, TM, YO, SM, MS, ST), Shiga University of Medical Science, Otsu, Shiga, Japan; Psychiatry Service (TN), Hachiman Sejukai Hospital, Omihachiman, Shiga, Japan; Psychiatry Service (SM), Toyosato Hospital, Toyosatocho, Inukami County, Shiga, Japan; Psychiatry Service (MS), Takashima General Hospital, Takashimacho, Takashima County, Japan; Health Administration Center (TS), Shiga University of Medical Science, Seta Tsukinowacho, Otsu, Shiga, Japan.

Address correspondence to: Kazutaka Shimoda, M.D., Ph.D., Department of Psychiatry, Shiga University of Medical Science, Seta Tsukinowacho, Otsu, Shiga, 520-21, Japan

Received May 13, 1994; revised November 8, 1994; accepted November 11, 1994.
TCAs varied considerably between individuals treated even with similar doses of the same drug, which suggests that such pharmacokinetic variation reflected interindividual differences in drug metabolism (Hammer and Sjöqvist 1967). Alexanderson et al. (1969) also investigated steady-state plasma levels of nortriptyline in monozygotic and dizygotic twins, concluding that variability in steady-state plasma concentrations between individuals was mostly genetically determined.

Clomipramine (C), a chlorinated analog of imipramine, has become one of the most frequently used TCAs since 1960s for the treatment of psychiatric illness. Clomipramine has been reported to be a potent inhibitor of serotonin reuptake, and its active desmethylated and/or hydroxylated metabolites inhibit the reuptake of both serotonin and/or noradrenaline.

Despite the widespread use of $\mathrm{C}$, relatively little is known about its metabolism and phamacokinetics in humans. By analogy with the metabolism of imipramine, the major route of biotransformation of $\mathrm{C}$ is des- 

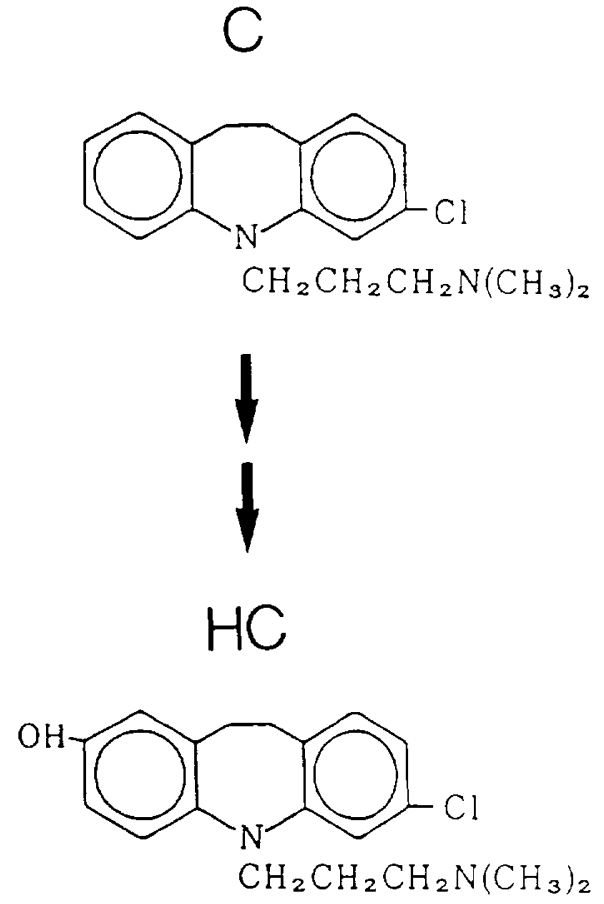

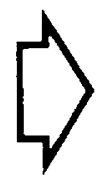<smiles>C=NCCNc1ccccc1C</smiles><smiles>I[IH]</smiles><smiles>O</smiles><smiles>C=CCNc1ccc(O)cc1CCc1ccc(Cl)cc1</smiles>

$\mathrm{CH}_{2} \mathrm{CH}_{2} \mathrm{CH}_{2} \mathrm{NHCH}_{3}$

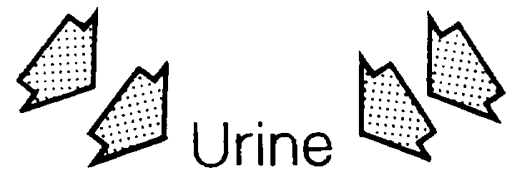

Figure 1. Structural formulae of clomipramine (C), N-desmethylclomipramine (DC), 8-hydroxyclomipramine (HC), and 8-hydroxy-N-desmethylclomipramine (HDC). Metabolic pathways of $\mathrm{C}$ are also shown. Solid, open, and shaded arrows show hydroxylation clearance, desmethylation clearance, and the combined effect of conjugation and direct renal excretion of hydroxylated metabolites.

methylation at nitrogen of the $\mathrm{N}$-demethylamino group (see Figure 1). Other metabolic pathways comprise hydroxylation clearance and conjugation of hydroxylated metabolites, as shown in Figure 1.

Desmethylclomipramine (DC), 8-hydroxyclomipramine (HC), 8-hydroxy- $\mathrm{N}$-desmethylclomipramine (HDC), 8-hydroxyclomipramine glucuronide (HCG), and 8-hydroxy-N-desmethylclomipramine glucuronide (HDCG), have been found in the plasma of patients who were administered clomipramine hydrochloride (Nielsen et al. 1992).

This study was conceived to investigate the following matters:

1. The plasma concentrations of $C, H C, D C, H D C$, HCG, and HDCG in psychiatric patients regularly receiving clomipramine hydrochloride PO.

2. The impact of age, nutritional state, daily dose of clomipramine hydrochloride, administration of benzodiazepine derivatives, smoking, or gender on desmethylation, hydroxylation of $C$, and glucuronidation of hydroxylated metabolites of $\mathrm{C}$ (i.e., HC and HDC).

3. Interindividual variations of desmethylation, hydroxylation of $\mathrm{C}$, and glucuronidation of $\mathrm{HC}$ and HDC.

To our knowledge, this is the first comprehensive report dealing with desmethylation, hydroxylation, and glucuronidation of TCAs in a sizable Asian population. The present report may be informative when compared with previous data on metabolism of TCAs in other ethnic groups.

\section{SUBJECTS AND METHODS}

\section{Subjects}

One hundred and eight patients (male: $n=32$; female: $n=76$ ) receiving clomipramine hydrochloride (ANAFRANIL ${ }^{\circledR}$, Ciba-Geigy Japan Ltd., Takarazuka, Japan) participated in this study. Of these patients 87 patients were hospitalized at the Shiga University of Medical Science Hospital, Toyosato Hospital, or Hirosaki University Hospital for the treatment of their psychiatric illnesses, while 21 subjects were under treatment at the outpatient clinic of these hospitals. Informed consent was obtained from each subject. 
Patients on neuroleptics, barbiturates, and/or oral contraceptives as subordinate prescriptions were excluded because such drugs are known to alter the metabolism (Daniel and Melzacka 1986; Krüger et al. 1986) and/or plasma levels (Alexanderson et al. 1969; Br $\phi$ sen et al. 1986a; Edelbroek et al. 1987) of TCAs. Benzodiazepines in usual doses were allowed to be administered as sleep inducers when patients complained of sleep disturbances since benzodiazepines have been reported not to influence substantially the metabolism of TCAs (Bertilsson et al. 1988; Otani et al. 1987; Träskman et al. 1979). The drugs and their doses were: flunitrazepam (ROHYPNOL ${ }^{\circledR}$, Nippon Roche K.K., Tokyo, Japan) 1-4 mg/day; nitrazepam (BENZALINE ${ }^{\circledR}$, Shionogi \& Co., Osaka, Japan), $5 \mathrm{mg} /$ day; flurazepam (BENOZIL ${ }^{\circledR}$, Kyowa Hakko Co., Ltd., Tokyo, Japan), $30 \mathrm{mg} /$ day, diazepam (HORIZON ${ }^{\circledR}$; Yamanouchi Pharmaceutical Co., Ltd., Tokyo, Japan), $5 \mathrm{mg} /$ day; bromazepam (LEXOTAN ${ }^{\circledR}$, Nippon Roche, Tokyo, Japan), 5 $\mathrm{mg} /$ day; triazolam (HALCION ${ }^{\circledR}$, Japan Upjohn Ltd., Tokyo, Japan), $0.25 \mathrm{mg} /$ day; etizolam (DEPAS ${ }^{\circledR}$, Yoshitomi Pharmaceutical Industries, Ltd., Osaka, Japan), $1 \mathrm{mg} /$ day; brotizolam (LENDORMIN ${ }^{\circledast}$, Nippon Boehinger-Ingelheim, Kawanishi, Japan), $0.25 \mathrm{mg} /$ day, haloxazolam (SOMELIN ${ }^{\circledR}$, Sankyo Co., Ltd., Tokyo, Japan), $10 \mathrm{mg} /$ day; rilmazafone (RHYTHMY ${ }^{\circledR}$, Shionogi \& Co., Ltd., Osaka, Japan), $1 \mathrm{mg} /$ day.

Demographic data, medical histories, and laboratory data including hematology, serology, electrolytes, and urine analysis were collected for each patient. Patients with physical illnesses were excluded from this study.

The one hundred and eight patients consisted of 32 men and 76 women, and their ages ranged from 17 to 73 (mean $\pm \mathrm{SD}=44.5 \pm 14.5$ ) years. Diagnoses were made by semistructured interviews using DSM-III-R criteria (American Psychiatric Association 1987).

More than $80 \%$ of the patients $(89 / 108)$ were diagnosed as having a major depressive episode. Their body weights and heights were in a range of 32.3 to 80.8 (mean $\pm \mathrm{SD}=52.3 \pm 9.5) \mathrm{kg}$ and 136 to $179.5(157.1 \pm$ $10.3) \mathrm{cm}$, respectively, body mass index $\{\mathrm{BMI}=[$ body weight $\left.(\mathrm{kg})] /[\text { height }(\mathrm{m})]^{2}\right\}$ was calculated for each subject as an index of his or her nutritional state.

\section{Blood Sampling and Administration of Clomipramine Hydrochloride}

Daily doses of clomipramine hydrochloride were titrated in a range of 30 to $250(111.8 \pm 52.3) \mathrm{mg} /$ day, or 0.40 to $5.10(2.18 \pm 1.08) \mathrm{mg} / \mathrm{kg}$ body weight. ANAFRANIL ${ }^{\circledR}$ (Ciba-Geigy Japan Ltd., Takarazuka, Japan) tablets containing $10(57 \mathrm{~mol})$ or $25 \mathrm{mg}$ (142 mol) of clomipramine hydrochloride were administered orally with tap water. For inpatients, nurses were instructed to confirm intake of the prescribed drugs. Out- patients were instructed not to take alcohol and also instructed to report if they took medications such as laxatives, antihistamines, analgesics, or contraceptives. Their family members were entrusted with the care of the prescribed drugs and instructed to confirm regular intake of the drugs. Patients were maintained for at least 14 days at the same dosage until the time of blood sampling. Blood $(20 \mathrm{ml})$ was collected at 6 A.M., 12 hours after the evening dose, into heparinized Venoject ${ }^{\circledR}$ tubes (Terumo Japan, Tokyo, Japan) and centrifuged at $1,000 \mathrm{~g}$. Aliquots of plasma were frozen and stored at $-80^{\circ} \mathrm{C}$ until assayed. Seventy-four additional samples were obtained from 52 patients, 2, 4, or 6 weeks after the furst blood sampling, and a total of 182 samples were collected.

\section{Determination of Plasma Levels of $C$ and Its Metabolites DC, Unconjugated HDC and Unconjugated $\mathrm{HC}$}

Plasma levels of $C$ and its metabolites DC, unconjugated HDC, unconjugated HC were determined by highperformance liquid chromatography (HPLC) according to the procedure of Fekete et al. (1981) with minor modifications. ${ }^{1}$ The recoveries of $\mathrm{C}, \mathrm{DC}, \mathrm{HC}$, and internal standard were $85 \%$ to $90 \%$ and approximately $50 \%$ for HDC. The intraassay coefficients of variation (CVs) were $2 \%$ to $4 \%(n=10)$ for each compound. The interassay CVs were $10 \%$ to $13 \%(n=7)$ for each compound.

\section{Deconjugation and Determination of Plasma Levels of HCG and HDCG}

HCG and HDCG in plasma were deconjugated by the method of Bock et al. (1982) and Bock et al. (1983) with minor modifications. ${ }^{1}$ Five hundred microliter of sample plasma was incubated with $2,500 \mathrm{U}$ of $\beta$-glucuronidase ( $\beta$-D-Glucuronide glucuronosohydrolase from Helix pomatia, Type H-2; SIGMA Chemicals, MO, USA). The optimum hydrolytic condition, which provided maximum yield of unconjugated metabolites, was determined by the preliminary experiments using pooled plasma that contained $10 \%$ of urine from a subject who was administered $25 \mathrm{mg} /$ day IV of clomipramine hydrochloride for 14 days.

Because the pure HCG or HDCG was not available, we could not determine the absolute efficiency of the enzymatic hydrolysis. However, interassay CVs $(n=$ 6) for total HC (i.e., HC + HCG) and total HDC (i.e., $\mathrm{HDC}+\mathrm{HDCG})$ were $9 \%(3,707 \pm 345 \mathrm{nmol} / \mathrm{l})$ and $3 \%$

${ }^{1}$ Detailed description of analytical procedures should be requested from K. Shimoda. 
$(2,954 \pm 92 \mathrm{nmol})$, respectively. Intraassay CVs $(n=$ 10 ) for total HC and total HDC were $7 \%$ and $7 \%$, respectively.

\section{Calculation of Metabolic Ratios for Desmethylation, Hydroxylation, and Glucuronidation Ratio}

Because the main oxidative pathway of $\mathrm{C}$ is desmethylation to $\mathrm{DC}$ and plasma concentrations of $\mathrm{C}$ and $\mathrm{HC}$ are strongly dependent on $\mathrm{N}$-desmethylation (BalantGorgia et al. 1986), the C-to-DC ratio was defined as the metabolic ratio for desmethylation (MRD), that is, $M R D=C / D C$, and the DC-to-total HDC ratio [i.e., $\mathrm{DC} /(\mathrm{HDC}+\mathrm{HDCG})]$ was defined as the metabolic ratio for hydroxylation (MRH). The ratio of $\mathrm{HC}+\mathrm{HDC}$ to HCG + HDCG [i.e., (HC + HDC)/(HCG + HDCG)] was defined as the glucuronidation ratio (GR) because a significantly positive correlation was observed between HC/HCG and HDC/HDCG $(n=182 ; \mathrm{df}=180$; $r=0.48 ; p<.001)$, which means that these two glucuronidation pathways (i.e., $\mathrm{HC} \rightarrow \mathrm{HCG}, \mathrm{HDC} \rightarrow$ HDCG) are regulated by an identical isozyme.

\section{RESULTS}

\section{Plasma Levels of $\mathrm{C}$ and Its Unconjugated Metabolites}

There were pronounced interindividual variations in the total unconjugated drug concentrations (i.e., $\mathrm{C}+$ $\mathrm{DC}+\mathrm{HC}+\mathrm{HDC}$ ) and those of each plasma concentration of unconjugated compound; that is, the total unconjugated drug concentrations ranged from 174 to $8,753 \mathrm{nmol} / 1$ (means $\pm \mathrm{SD}=1,851 \pm 1,290 \mathrm{nmol} / \mathrm{l}$ ), the concentrations of $C$ ranged from 47 to $2,992 \mathrm{nmol} / 1$ $(566 \pm 450 \mathrm{nmol} / \mathrm{l}$, those of DC from 29 to $4,242 \mathrm{nmol} / 1$ $(698 \pm 604 \mathrm{nmol} / 1)$, of HC from 39 to $983 \mathrm{nmol}(249.3 \pm$ $147.0 \mathrm{nmol} / \mathrm{l})$, and of HDC from 0 to $1,012 \mathrm{nmol} / 1$ (339 \pm $225 \mathrm{nmol} / \mathrm{l})$. Significant positive correlations were observed between total unconjugated drug concentrations $(r=0.79 ; n=182 ; \mathrm{df}=180 ; p<.001)$ or concentrations
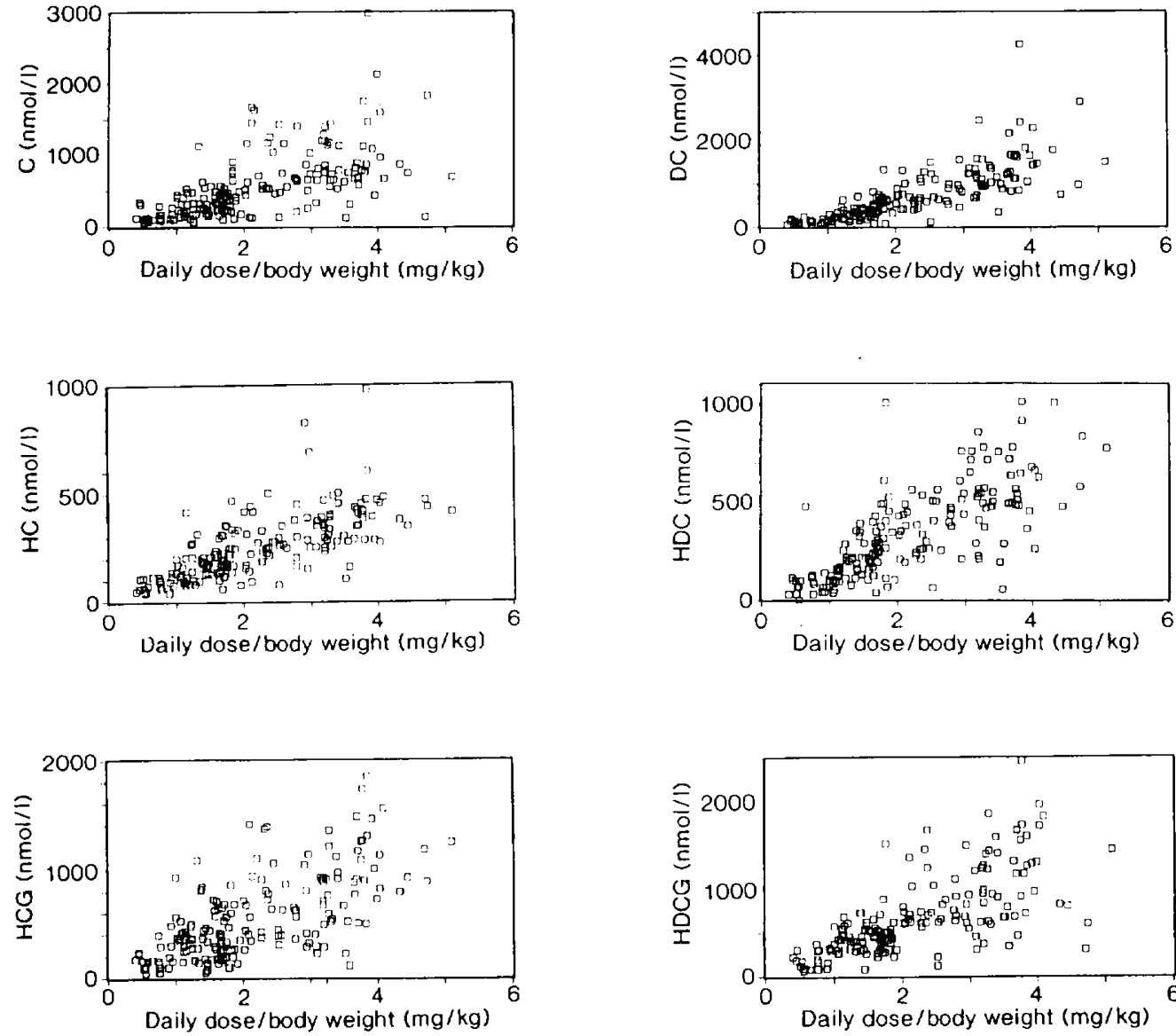

Figure 2. A significant and positive correlation between the daily dose of clomipramine hydrochloride per body weight and plasma levels of the parent compound, its desmethylated metabolites, unconjugated hydroxylated metabolites, or conjugated hydroxylated metabolites (C: clomipramine, DC: N-desmethylclomipramine, HC: 8-hydroxyclomipramine, HDC: 8-hydroxy-N-desmethylclomipramine, HCG: 8-hydroxyclomipramine glucuronide, HDCG: 8-hydroxy-N-desmethylclomipramine glucuronide). Coefficients of correlation are $0.61,0.78,0.70,0.74,0.65$, and 0.65 for C, DC, HC, HDC, HCG, and $\mathrm{HDCG}$, respectively $(n=182 ; \mathrm{df}=180 ; p<.001$, respectively). 
of each unconjugated compound in plasma and daily doses of clomipramine hydrochloride $(\mathrm{mg} / \mathrm{kg}$ body weight) $(r=0.61,0.78,0.70$, and 0.74 for $\mathrm{C}, \mathrm{DC}, \mathrm{HC}$, and HDC; $n=182 ; \mathrm{df}=180 ; p<.001$, respectively; see Figure 2).

\section{Plasma Levels of Conjugated HCG and HDCG}

Incubation of each sample with $\beta$-glucuronidase before extraction did not increase plasma concentrations of DC and $C$ (average factor $=0.98$ and 0.97 , respectively), while the deconjugation of each sample increased the plasma concentrations of $\mathrm{HC}$ and $\mathrm{HDC}$ by average factors of 3.36 and 3.61 , respectively.

Plasma concentrations of HCG and HDCG were determined by total HC and HDC (concentrations after hydrolysis) minus unconjugated HC or HDC (concentrations without hydrolysis), respectively. There were pronounced interindividual variations in the conjugated hydroxylated drug concentrations (i.e., HCG and HDCG). Concentrations of HCG were 45 to 1,855 $\mathrm{nmol} / 1(561 \pm 381 \mathrm{nmol} / \mathrm{l}) ;$ of HDCG, 64 to $2,464 \mathrm{nmol} / 1$ $(676 \pm 450 \mathrm{nmol} / \mathrm{l})$; while significant positive correlations were observed between conjugated hydroxylated drug concentrations (HCG, $r=0.65$; HDCG, $r=0.65, n=$ $182, \mathrm{df}=180, p<.001$, respectively) and the daily dose of clomipramine ( $\mathrm{mg} / \mathrm{kg}$ body weight) as shown in Figure 2.

\section{Impact of Age, Nutritional State, Daily Dose of Clomipramine Hydrochloride, Administration of Benzodiazepine Derivatives, Smoking or Gender on Desmethylation, Hydroxylation of $\mathrm{C}$ and Glucuronidation of Hydroxylated Metabolites of $\mathbf{C}$} From plasma concentrations of $C, D C, H C, H D C, H C G$, and HDCG the metabolic ratios representative of des- methylation, hydroxylation, and glucuronidation in each subject were determined, and the impact of age, nutritional state (= BMI), daily dose of clomipramine hydrochloride, administration of benzodiazepine derivatives, smoking, gender, or age on desmethylation, hydroxylation of clomipramine, and glucuronidation of hydroxylated metabolites of clomipramine were analyzed.

MRD. Significant relationship between daily dose of clomipramine $(\mathrm{mg} / \mathrm{kg}$ body weight) and MRD was detected $(r=0.31 ; \mathrm{df}=180 ; p<.001)$. The mean $\mathrm{CV}$ of $M R D$, representative of intraindividual variation, was $18.4 \%$. The MRDs were averaged in each of 52 patients whose blood samples were taken more than twice in order to calculate the individual MRD. No significant relationship was observed between age of subjects and individual MRD $(r=0.08 ; n=108 ; \mathrm{df}=106 ; \mathrm{NS})$. No significant relationship between $\mathrm{BMI}$ and individual MRD was detected either $(r=0.07 ; n=108$; df = 106; NS).

A three-way analysis of variance (three-way ANOVA) revealed that gender and smoking had significant effects on MRDs while administration of benzodiazepines had no significant effect at all (Table 1).

MRH. Significant relationship between daily dose of clomipramine ( $\mathrm{mg} / \mathrm{kg}$ body weight) and $\mathrm{MRH}$ was observed $(r=0.53 ; \mathrm{df}=180 ; p<.001)$. The mean $\mathrm{CV}$ of $\mathrm{MRH}$, representative of intraindividual variation, was $15.6 \%$. The MRDs were averaged in each of 52 patients whose blood samples were taken more than twice in order to calculate the individual MRH. No significant relationship was observed between age of subjects and individual MRH ( $r=0.14 ; n=108 ; \mathrm{df}=106 ; \mathrm{NS})$. No significant relationship between BMI and individual MRH was detected either ( $r=0.08 ; n=108 ; \mathrm{df}=106 ; \mathrm{NS})$. A three-way ANOVA revealed that gender and smok-

Table 1. Results of Analysis of Effect of Gender, Benzodiazepines, and Smoking on MRD by Three-way ANOVA

\begin{tabular}{lccccc}
\hline $\begin{array}{l}\text { Source of } \\
\text { Variation }\end{array}$ & $\begin{array}{l}\text { Sum of } \\
\text { Square }\end{array}$ & df & $\begin{array}{c}\text { Mean } \\
\text { Square }\end{array}$ & F & $p$ \\
\hline Main effects & 7.96 & 3 & 2.65 & 2.69 & 0.050 \\
Gender & 6.07 & 1 & 6.07 & 6.16 & 0.015 \\
Benzodiazepine & 0.56 & 1 & 0.56 & 0.57 & 0.454 \\
Smoking & 3.98 & 1 & 3.98 & 4.04 & 0.047 \\
\hline
\end{tabular}

Table 2. Results of Analysis of Effect of Gender, Benzodiazepines, and Smoking on MRH by Three-way ANOVA

\begin{tabular}{lccccc}
\hline $\begin{array}{l}\text { Source of } \\
\text { Variation }\end{array}$ & $\begin{array}{l}\text { Sum of } \\
\text { Square }\end{array}$ & df & $\begin{array}{c}\text { Mean } \\
\text { Square }\end{array}$ & F & $p$ \\
\hline Main effects & 0.70 & 3 & 0.23 & 2.21 & 0.091 \\
Gender & 0.46 & 1 & 0.46 & 4.40 & 0.039 \\
Benzodiazepine & 0.02 & 1 & 0.02 & 0.14 & 0.707 \\
Smoking & 0.51 & 1 & 0.51 & 4.87 & 0.030 \\
\hline
\end{tabular}


Table 3. Results of Analysis of Effect of Gender, Benzodiazepines, and Smoking on GR by Three-way ANOVA

\begin{tabular}{lccccc}
\hline $\begin{array}{l}\text { Source of } \\
\text { Variation }\end{array}$ & $\begin{array}{l}\text { Sum of } \\
\text { Square }\end{array}$ & df & $\begin{array}{c}\text { Mean } \\
\text { Square }\end{array}$ & F & $\boldsymbol{p}$ \\
\hline Main effects & 3.16 & 3 & 1.05 & 5.79 & 0.010 \\
Gender & 0.69 & 1 & 0.69 & 3.78 & 0.055 \\
Benzodiazepine & 1.51 & 1 & 1.51 & 8.30 & 0.005 \\
Smoking & 0.18 & 1 & 0.18 & 0.98 & 0.325 \\
\hline
\end{tabular}

ing had significant effects on MRHs while administration of benzodiazepines had no significant effect at all (Table 2).

GR. No significant relationship between daily dose of clomipramine ( $\mathrm{mg} / \mathrm{kg}$ body weight) and GR was observed $(r=0.01 ; \mathrm{df}=180 ; \mathrm{NS})$. The mean CV of GR, representative of intraindividual variation, was $16 \%$. The GRs were averaged in each of 52 patients whose blood samples were taken more than twice in order to calculate the individual GR. No significant relationship was observed between age of subjects and individual GR $(r=0.03 ; n=108 ; \mathrm{df}=$ 106; NS). No significant relationship between BMI and individual GR was detected either $(r=0.15 ; n=108$; $\mathrm{df}=106$; NS).

A three-way ANOVA revealed that administration of benzodiazepines had significant effects on GRs while effect of gender on GRs reached almost significance level $(p=0.055$, Table 3$)$.

\section{Interindividual Variations of Individual MRD and MRH}

The individual metabolic ratios representative of desmethylation and hydroxylation (MRD and MRH, respectively) varied substantially, ranging from 0.25 to $9.06(1.17 \pm 1.02)$ and from 0.14 to $2.04(0.63 \pm 0.32)$, respectively.

Figure 3 shows the distribution of individual metabolic ratio for desmethylation of C (i.e., MRD). Approximately 36 -fold interindividual variations $(0.25-9.06)$ were observed in the MRD. Each value was subjected to natural logarithmic transformations in order to draw frequency distribution histograms of the MRD, as shown in the upper part of Figure 3. Ln(MRD) ranging from about -1.5 to 2.25 appeared to have a normal distribution pattern. A probit plot of $\operatorname{Ln}(\mathrm{MRD})$ (lower part of Figure 3) gave a straight line, which is consistent with a normal distribution.

Figure 4 shows the distribution of individual metabolic ratio for hydroxylation of $\mathrm{C}$ (i.e., $\mathrm{MRH})$. Approximately 14-fold interindividual variations of $\mathrm{MRH}$, ranging from 0.14 to 2.04 were observed. $\operatorname{Ln}(\mathrm{MRH})$ ranging from -2.0 to 0.75 appeared to have a normal distribution pattern. When the MRH data were transformed into a probit plot (lower part of Figure 4), the probit plot patterns were linear, which meant that the MRH data had a normal distribution pattern.

\section{Interindividual Variation of GR}

The individual GR exhibit pronounced interindividual difference, ranging from 0.13 to $3.69(0.56 \pm 0.45)$. Figure 5 shows the distribution of individual GR. Approximately 28 -fold interindividual variations (0.13-3.69) were observed in GR. Each value was subjected to natural logarithmic transformations in order to draw frequency distribution histograms of GR as shown in the upper part of Figure 5. $\mathrm{Ln}(\mathrm{GR})$ ranging from ca. -2.0 to 1.3 appeared to have a normal distribution pattern. A probit plot of $\operatorname{Ln}(\mathrm{GR})$ (lower part of Figure 5) showed
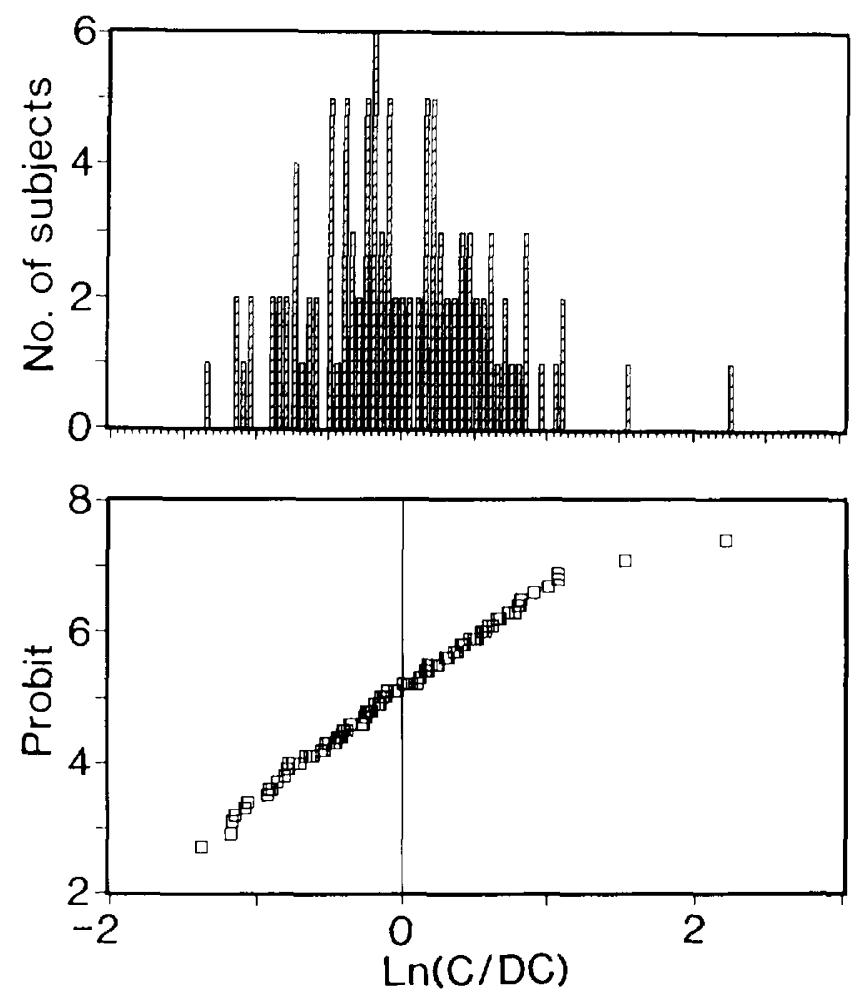

Figure 3. Frequency histogram (top) and probit plot, or cumulative frequency distribution (bottom) of $\mathrm{MRD}$ (i.e., C/DC) in 108 subjects studied. 

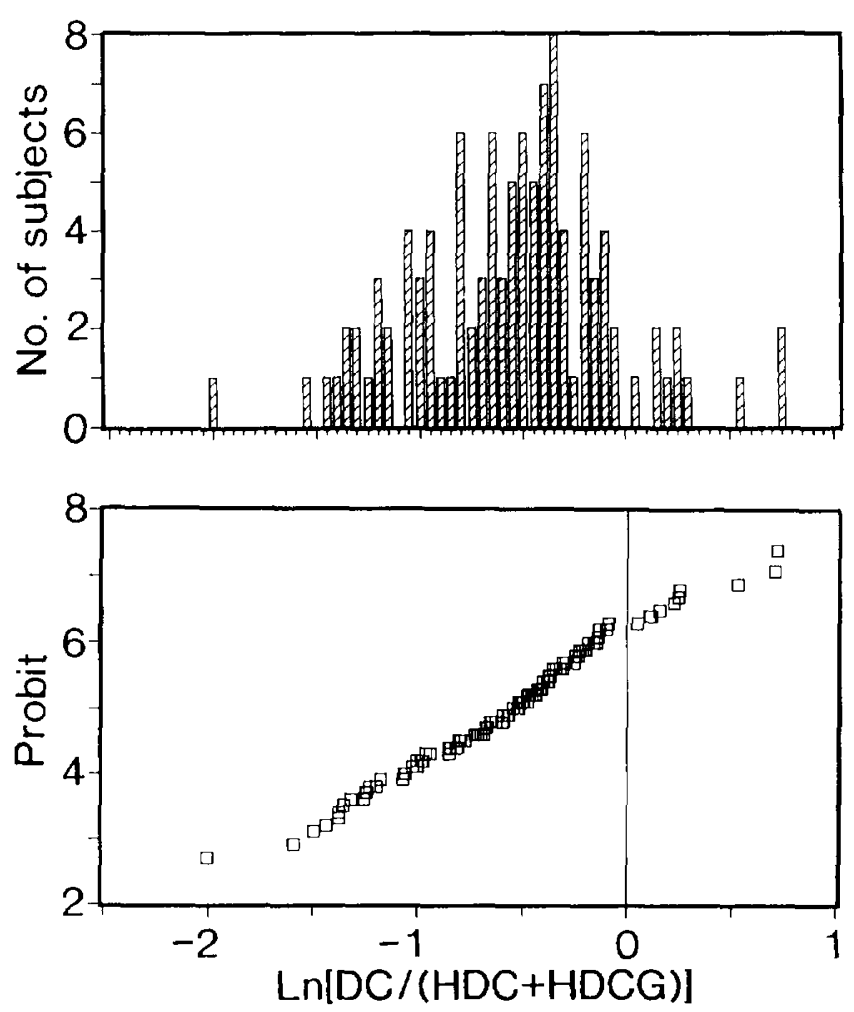

Figure 4. Frequency histogram (top) and probit plot, or cumulative frequency distribution (bottom) of $\mathrm{MRH}$ [i.e., $\mathrm{DCl}$ $(\mathrm{HDC}+\mathrm{HDCG})]$ in 108 subjects studied.

a straight line, which meant GRs had a normal distribution.

\section{DISCUSSION}

The present study was designed to know plasma concentrations of C, DC, HC, HDC, HCG, and HDCG and to explore the impact of various factors that have been reported to influence the metabolism of TCAs such as age, nutritional state, daily dose of the drug, administration of benzodiazepine derivatives, smoking, or gender on $\mathrm{C}$ metabolism. We also tried to investigate the extent of interindividual variations of $C$ metabolism by determining individual metabolic ratios for hydroxylation, desmethylation, and glucuronidation from the steady-state plasma levels of $C$ and its metabolites, including glucuronide conjugates.

This design provides various advantages such as the easy availability of the data. It can benefit patients in ordinary clinical settings, involves minimal interference with treatment planning for patients, and enables the collection of sizable data and therapeutic drug monitoring simultaneously.

Of course, simultaneous phenotyping by using
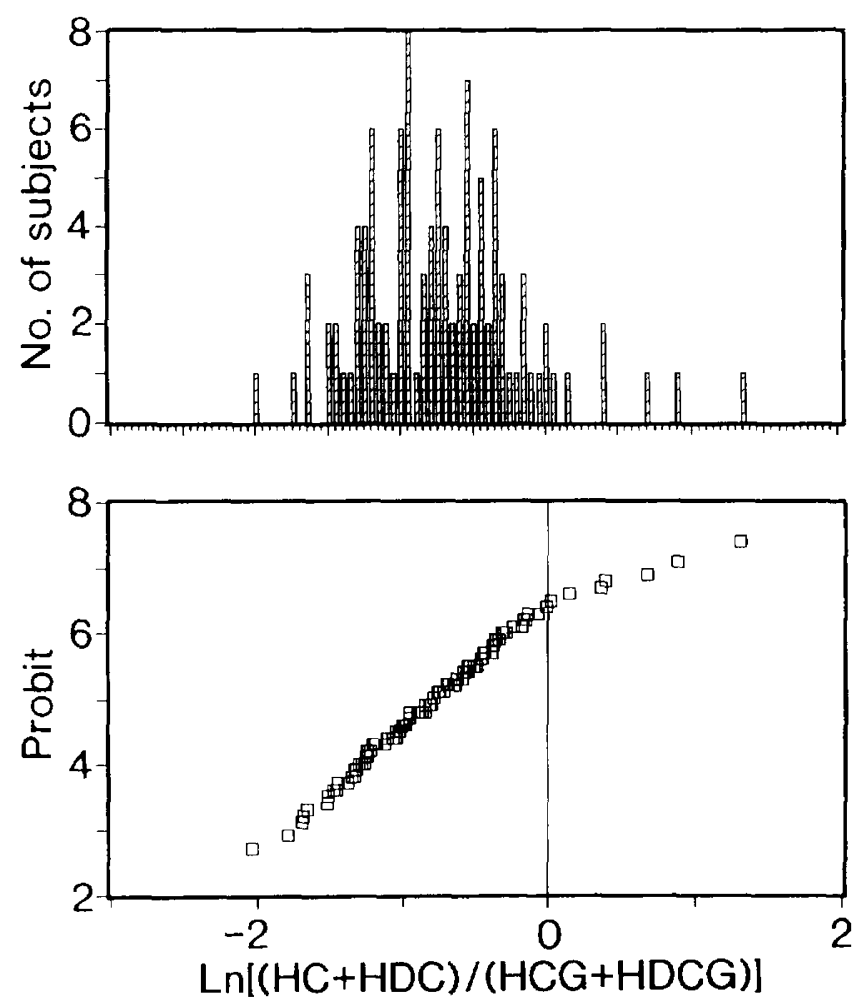

Figure 5. Frequency histogram (top) and probit plot, or cumulative frequency distribution (bottom) of GR (i.e., [ $[\mathrm{HC}+$ $\mathrm{HDC}) /(\mathrm{HCG}+\mathrm{HDCG})]$ in 108 subjects studied.

probe drugs, such as debrisoquine, sparteine, or mephenytoin, is informative in this kind of study, because polymorphism of oxidation of some drugs, including sparteine and debrisoquine, has been reported to be associated with interindividual variation in hydroxylation of various TCAs: amitriptyline (Balant-Gorgia et al. 1982; Mellström et al. 1983, 1986), nortriptyline (Mellström et al. 1981; Nordin et al. 1985; Woolhouse et al. 1984); imipramine (Brøsen et al. 1986b) and desipramine (Bertilsson and Åberg-Wistedt 1983; Brøsen et al. 1986b; Spina et al. 1984, 1987). In addition, desmethylation of imipramine has been reported to be partly mediated by mephenytoin oxygenase (Gram et al. 1990; Skjelbo et al. 1991), which means that poor metabolizers of mephenytoin cannot desmethylate imipramine efficiently. However, such probe drugs have not been approved by the Japanese Ministry of Health and Welfare for clinical use, and the administration of such drugs to patients poses an ethical problem in Japan. Dextromethorphan is available as an over-the-counter drug in our country and is used as one of the substitutes for probe drugs such as debrisoquine, sparteine, or mephenytoin. Genotyping using the molecular biological technique is also an alternative for such probe drug tests. 


\section{Plasma Levels of C, DC, HC, HDC}

Della Corte et al. (1979) reported a significant correlation between the daily dose of clomipramine hydrochloride per body weight and plasma levels of $C$ and DC. Consistent with that study, we obtained data that suggested strong positive correlations between plasma concentrations of each unconjugated compound and daily doses of clomipramine hydrochloride per body weight (see Figure 2), thus indicating that the daily dose of clomipramine hydrochloride per body weight is an important determinant of plasma levels of $C$ and its metabolites.

\section{Plasma Concentrations of HCG and HDCG}

Incubation of each sample with $\beta$-glucuronidase before extraction did not increase plasma concentration of DC and $C$, which means that glucuronide conjugate of $C$ or DC could not be detected by at least the assay system used in this study. On the contrary, plasma concentrations of $\mathrm{HC}$ and HDC were increased after enzymatic hydrolysis, which means that hydroxylated metabolites of $C$ are exclusively subjected to conjugation. These findings are consistent with the report of Nielsen et al. (1992); however, it is contradictory to the fact that the quarternary ammonium-linked glucuronide of amitriptyline has been found in urine from patients receiving therapeutic doses of amitriptyline, which suggests direct conjugation of the parent compound, amitriptyline (Dahl-Puustinen et al. 1987, 1989; Lehman et al. 1983).

Nielsen et al. (1992) reported that incubation of samples from Caucasian subjects who were treated with clomipramine hydrochloride with $\beta$-glucuronidase/ arylsulfatase increased the plasma concentrations of $\mathrm{HC}$ and HDC by average factors of about 7 and 3, respectively, while Suftin et al. (1988) reported that appreciable glucuronide conjugate accumulation was observed in patients treated with $200 \mathrm{mg} /$ day of imipramine hydrochloride with average serum concentration ratios of 8.1 and 6.2 for 2-hydroxyimipramine glucuronide/2hydroxyimipramine and 2-hydroxydesipramine glucuronide/2-hydroxydesipramine, respectively. Bock et al. (1982) reported an average serum concentration ratio ( = 2-hydroxydesipramine glucuronide/2-hydroxydesipramine) of approximately 12 in plasma from subjects treated with $2.5 \mathrm{mg} / \mathrm{kg} /$ day of desipramine, while Bock et al. (1983) and Lieberman et al. (1985) reported average ratio [ $=$ (unconjugated 10-hydroxyamitriptyline + unconjugated 10-hydroxynortriptyline)/(10hydroxyamitriptyline glucuronide +10 -hydroxynortriptyline glucuronide) of about 4 and 1, respectively. Deconjugation of our samples increased the plasma concentrations of $\mathrm{HC}$ and HDC by average factors of 3.36 and 3.61, respectively (i.e., $\mathrm{HCG} / \mathrm{HC}=2.36$ and
HDCG/HDC $=2.61$, which is $50 \%$ less than the results from Bock et al. (1982), Nielsen et al. (1992), and Suftin et al. (1988).

Although one of the possible explanations for this discrepancy could be the low efficiency of hydrolysis used in this study, the condition used in this study was confirmed to give sufficiently high efficiency of enzymatic hydrolysis by preliminary experiments. In addition, hydrolysis of reference samples (pooled plasma that contained $10 \%$ of urine from a subject who was administered $25 \mathrm{mg}$ per day of clomipramine hydrochloride intravenously for 14 days) increased plasma concentrations of HC (up to ca. 3,700 nmol/l) and of HDC (up to ca. 3,000 nmol/l) by average factors of ca. 14 and 10, respectively, which indicates the high efficiency of our method for enzymatic hydrolysis.

A second possible reason for this discrepancy is substrate specificity of isozyme of glucuronosyltransferase. Glucuronidation is catalyzed by a family of closely related isozymes that have different but overlapping substrate specificities. The existence of multiple forms of this enzyme has been suggested (Siest et al. 1987).

A third possible reason is the existence of an interethnic difference in glucuronidation capacity. Because the subjects were all Japanese, we could not tell whether such an interethnic difference exists or not. However, interethnic difference in glucuronidation capacity has been reported using other drugs than TCAs (Yue et al. 1989).

\section{Impact of Administration of Age, Nutritional State, Benzodiazepine Derivatives, Smoking, or Gender on Desmethylation, Hydroxylation of $C$, and Glucuronidation of Hydroxylated Metabolites of $\mathrm{C}$}

No significant relationships were shown between age and individual capacities of desmethylation, hydroxylation, or glucuronidation of clomipramine. An increase in age has been reported to be associated with increased plasma levels of TCAs and their metabolites (Bertilsson et al. 1979; Kitanaka et al. 1982; Nies et al. 1977). However, positive association between age and plasma levels of TCAs and its metabolites is generally attributed to decreased renal clearance (Bertilsson et al. 1979; Cutler et al. 1981; Kitanaka et al. 1982; Nies et al. 1977), but not to decreased hepatic enzyme activity.

No significant relationships were shown between individual capacities of desmethylation, hydroxylation of clomipramine, or glucuronidation of hydroxylated metabolites of clomipramine and nutritional state in the present study, but nutritional state affects the glucuronidation of certain kinds of drugs [e.g., fenofibrate (Liu et al. 1991)]. 
No significant effect of administration of benzodiazepine derivatives on desmethylation and hydroxylation of clomipramine was detected in the present study, which seems to be consistent with previous reports (Bertilsson et al. 1988; Otani et al. 1987; Träskman et al. 1979). However, a more controlled study is necessary to clarify the matter because a few of the many kinds of benzodiazepines used in this study should not have been administered as they can be suspected to have interaction with metabolism of tricyclic antidepressants.

A significant effect of benzodiazepine administration on glucuronidation was observed, but no previous studies that include analyses of the effect of benzodiazepine administration on glucuronidation of TCAs have been reported so far.

Although a significant effect of smoking on desmethylation and hydroxylation of clomipramine was shown in this study, this observation does not contradict the fact that smoking induces some cytochrome enzymes (Jusko 1979).

Significant gender effects on desmethylation and hydroxylation were observed, with female subjects having a lower glucuronidation capacity of hydroxylated metabolites of clomipramine than did male subjects in the present study (GR: male vs. female 0.37 vs. 0.64 ). Although Someya et al. (1992) reported the extent of glucuronidation of haloperidol and reduced haloperidol, further analysis of their data revealed that glucuronidation capacity of female subjects was approximately $60 \%$ of those of male subjects, which is compatible with the result of the present study.

\section{Interindividual Variations of Desmethylation and Hydroxylation of Clomipramine}

Reference to several reports on the metabolism of TCAs in vivo provided controversial findings. Although metabolic ratios for desmethylation corresponding to MRD in this study for various TCAs showed 9- to 15-fold variations for imipramine (Br $\phi$ sen et al. 1986a, 1986b), 5-fold variations for clomipramine (Träskman et al. 1979), and 12- to 14-fold interindividual variations for amitriptyline (Bock et al. 1982; Breyer-Pfaff et al. 1982), respectively, Gram et al. (1977) and Kuss and Jungkunz (1986) reported approximately 80-fold interindividual variations of desmethylation of imipramine and clomipramine, respectively. Approximately 36 -fold interindividual variations in MRD were observed in our study.

Reference to the previous report on the metabolism of TCAs also suggested controversial findings for metabolic ratios for hydroxylation: metabolic ratios for hydroxylation calculated from steady-state concentrations exhibited 24-fold interindividual variations for im- ipramine (Brøsen et al. 1986a) and 20-fold interindividual variations for amitriptyline (Bock et al. 1982), respectively, while metabolic ratios for hydroxylation of desipramine had approximately 100-, 102-, and 150fold interindividual variations (Bock et al. 1983; Potter et al. 1982; Spina et al. 1984). Also Balant-Georgia et al. (1986) analyzed the data on steady-state concentrations of clomipramine and its hydroxylated and desmethylated metabolites and reported approximately 80 fold interindividual variations of hydroxylation of clomipramine.

Reference to previous reports using such probe drugs as sparteine, debrisoquine, or mephenytoin in a Japanese population might be useful in interpreting our data on desmethylation and hydroxylation. Although Nakamura et al. (1985) reported no poor metabolizers of debrisoquine in 100 Japanese subjects, Ishizaki et al. (1987) reported an incidence of poor metabolizers of sparteine as $2 \%$ in 84 Japanese subjects. Nakamura et al. (1985) also reported that the incidence of poor metabolizers of mephenytoin was $18 \%$, while Jurima et al. (1985) found that 7 of 31 Canadians of Japanese descent (incidence of $23 \%$ ) were poor mephenytoin metabolizers. From the results of probit analyses of MRD and MRH, no apparent poor desmethylators or poor hydroxylators were observed in our 108 subjects. Our data obtained on hydroxylation of $C$ appeared to be consistent with the result of Ishizaki et al. (1987), but our data on desmethylation contradict those of both Jurima et al. (1985) and Nakamura et al. (1985).

Four possible explanations can be made for these discrepancies. First, such probe drug studies were performed in the single-dose study design, while our data was obtained during chronic treatment of $C$. Second, chronic administration of clomipramine may induce the enzymes responsible for desmethylation and hydroxylation for $C$ and phenotypes of poor hydroxylators or desmethylators of clomipramine are masked. Third, a period of 2 weeks is too short to obtain the steady state, particularly in poor metabolizers. Fourth, the enzymes responsible for desmethylation of TCAs may not be identical to mephenytoin oxygenase (Gram et al. 1990; Skjelbo et al. 1991).

\section{Interindividual Variation of Glucuronidation of Hydroxylated Metabolites of $C$}

Approximately 28 -fold interindividual variation of GR, ranging from 0.13 to 3.69 were observed in 108 subjects investigated in this study.

Few studies on interindividual variation of glucuronidation of TCAs has been reported so far. However, Bock et al. reported an about fourfold interindividual variation of GR in 27 patients receiving amitriptyline (Bock et al. 1982), and Suftin et al. (1988) 
reported an approximately 13 -fold interindividual variation in GR in 14 subjects receiving $200 \mathrm{mg}$ of imipramine for 7 days. Interindividual variation in GR observed in this study seems to be larger than those of previous reports (Bock et al. 1982; Suftin et al. 1988), and this might be due to the difference in sample size between previous reports and ours.

\section{ACKNOWLEDGMENTS}

The authors express their gratitude to Drs. J. Szeszak and K. Scheibli, Ciba-Geigy Limited, Basel, Switzerland, for providing N-desmethylclomipramine hydrochloride, 8-hydroxyclomipramine base, 8-hydroxy-N-desmethylclomipramine hydrochloride; to Ciba-Geigy Japan Limited for providing clomipramine hydrochloride; and to Dr. Koichi Otani (Department of Psychiatry, Hirosaki University, Hirosaki, Japan) for collecting samples and for his invaluable advice and suggestions in preparing the manuscript. This research was partly supported by a grant-in-aid from the Japanese Ministry of Health and Welfare, the Japanese Ministry of Education, and a grant from the Pharmacopsychiatry Research Foundation.

\section{REFERENCES}

Alexanderson B, Price Evans DA, Sjöqvist F (1969): Steadystate plasma levels of nortriptyline in twins: Influence of genetic factors and drug therapy. Brit Med J 4:764-768

American Psychiatry Association (1987): Diagnostic and statistical manual of mental disorders, ed 3, rev., Washington, DC, American Psychiatry Association

Balant-Gorgia AE, Schulz P, Dayer P, Balant L, Kubli A, Gertsch C, Garrone G (1982): Role of oxidation polymorphism on blood and urine concentrations of amitriptyline and its metabolites in man. Arch Psychiatr Nervenkr 232:215-222

Balant-Gorgia AE, Balant LP, Genet C, Dayer P, Aeschlimann JM, Garrone G (1986): Importance of oxidative polymorphism and levomepromazine treatment on the steadystate blood concentrations of clomipramine and its major metabolites. Eur J Clin Pharmacol 31:449-455

Bertilsson L, Åberg-Wistedt A (1983): The debrisoquine hydroxylation test predicts steady state plasma levels of desipramine. Br J Clin Pharmacol 15:388-390

Bertilsson L, Mellström B, Sjöqvist F (1979): Pronounced inhibition of noradrenaline uptake by 10-hydroxymetabolites of nortriptyline. Life Sci 25:1285-1292

Bertilsson L, Äberg-Wistedt A, Liden A, Otani K, Spina E (1988): Alprazolam does not inhibit the metabolism of nortriptyline in depressed patients or inhibit the metabolism of desipramine in human liver microsomes. Ther Drug Monit 10:231-233

Bock JL, Giller E, Gray S, Jatlow P (1982): Steady-state plasma concentrations of cis- and trans-10-OH amitriptyline metabolites. Clin Pharmacol Ther 31:609-616

Bock JL, Nelson JC, Gray S, Jatlow PI (1983): Desipramine hydroxylation: Variability and effect of antipsychotic drugs. Clin Pharmacol Ther 33:322-328
Breyer-Pfaff U, Gaertner HJ, Kreuter F, Scharek G, Brinkschulte M, Wiatr R (1982): Antidepressant effect and pharmacokinetics of amitriptyline with consideration of unbound drug and 10-hydroxynortryptyline plasma levels. Psychopharmacol 76:240-244

Brфsen K, Gram LF, Klysner R, Bech P (1986a): Steady state levels of imipramine and its metabolites: Significance of dose-dependent kinetics. Eur J Clin Pharmacol 30:43-49

Brфsen K, Klysner R, Gram LF, Otton SV, Bech P, Bertilsson L (1986b): Steady-state concentrations of imipramine and its metabolites in relation to sparteine/debrisoquine polymorphism. Eur J Clin Pharmacol 30:679-684

Cutler NR, Zavadil AP, Eisdorfer C, Ross RJ, Potter WZ (1981): Concentrations of desipramine in elderly women are not elevated. Am J Psychiatry 138:1235-1237

Dahl-Puustinen ML, Bertilsson L (1987): Formation of a quarternary $\mathrm{N}$-glucuronide of amitriptyline in human liver microsomes. Pharmacol Toxicol 61:342-346

Dahl-Puustinen ML, Åberg-Wistedt A, Bertilsson L (1989): Glucuronidation of amitriptyline in man in vivo. Pharmacol Toxicol 65:37-39

Daniel W, Melzacka M (1986): The effect of neuroleptics on imipramine desmethylation in rat liver microsomes and imipramine and desipramine level in the rat brain. Biochem Pharmacol 35:3249-3253

Della Corte L, Broadhurst AD, Sgaragli GD, Fillippini S, Heeley AF, James HD, Favarelli C, Pazzagli A (1979): Clinical response to tricyclic plasma levels during treatment with clomipramine. Br J Psychiatry 134:390-400

Edelbroek PM, Zitman FG, Knoppert-van der Klein EAM, van Putten PM, de Wolff FA (1987): Therapeutic drug monitoring of amitriptyline: Impact of age smoking and contraceptives on drug and metabolite levels in bulimic woman. Clin Chim Acta 165:177-187

Fekete J, Del Castilho P, Kraak JC (1981): Reversed-phase liquid chromatography for the separation of chlorpromazine, imipramine and some of their metabolites. J Chromatogr 204:319-327

Gram LF, S $\phi$ ndergaard I, Christiansen J, Petersen GO, Bech JP, Reisby N, Ibsen L, Ortmann J, Nagy A, Dencker SJ, Jacobsen O, Krautwald O (1977): Steady-state kinetics of imipramine in patient. Psychopharmacology (Berlin) 54:255-261

Gram LF, Br $\phi$ sen K, Skjelbo E, Sidrup S (1990): Significance of genetic polymorphism and selective P450 interactions in psychopharmacology. Clinical Neuropharmacology 13(suppl 2):559-560

Hammer W, Sjöqvist F (1967) Plasma levels of monomethylated tricyclic antidepressants during treatment with imipramine-like compounds. Life Sci 6:1895-1903

Ishizaki T, Eichelbaum M, Horai Y, Hashimoto K, Chiba K, Dengler HJ (1987): Evidence for polymorphic oxidation of sparteine in Japanese subjects. Br J Clin Pharmacol 23:482-485

Jusko WJ (1979): Influence of cigarette smoking on drug metabolism in man. Drug Metab Rev 9:221-228

Jurima M, Inaba T, Kadar D, Kalow W (1985): Genetic polymorphism of mephenytoin $\mathrm{p}\left(4^{\prime}\right)$-hydroxylation: Difference between Orientals and Caucasians. Br J Clin Pharmacol 19:483-487

Jacqz E, Hall SD, Branch RA (1986): Genetically determined 
polymorphism in drug oxidation. Hepatology 6:10201032

Kitanaka I, Ross RJ, Cutler NR, Zavadil AP, Potter WZ (1982): Altered hydroxydesipramine concentrations in elderly depressed patients. Clin Pharmacol Ther 31:51-55

Krüger R, Hözl G, Kuss HJ, Schefold L (1986): Influence of neuroleptics on the metabolism of tricyclic antidepressants - In vitro experiments with rat liver microsomes. Biol Psychiatry 21:1247-1257

Kuss HJ, Jungkunz G (1986): Nonliner pharmcokinetics of chlorimipramine after infusion and oral administration in patients. Prog Neuro-Psychopharmacol Biol Psychiatry 10:739-748

Lehman JP, Fenselau C, Depaulo JR (1983): Quarternary ammonium-linked glucuronides of amitriptyline, imipramine, and chlorpromazine. Drug Metab Dispos 11: 221-225

Lieberman JA, Cooper TB, Suckow RF, Steinberg H, Borenstein M, Brenner R, Kane JM (1985): Tricyclic antidepressant and metabolite levels in chronic renal failure. Clin Pharmacol Ther 37:301-307

Liu HF, Vinvent-Viry M, Galteau MM, Guéguen R, Magdalou J, Nicolas A, Leroy A, Siest G (1991): Urinary glucuronide excretion of fenofibric and clofibric acid glucuronide in man. Is it polymorphic? Eur J Clin Pharmacol 41:153-159

Mellström B, Bertilsson L, Säwe J, Schụlz HU, Sjöqvist F (1981): E- and Z-10-hydroxylation of nortriptyline: Relationship to polymorphic debrisoquine hydroxylation. Clin Pharmacol Ther 30:189-193

Mellström B, Bertilsson L, Lou Y-C, Säwe J, Sjöqvist F (1983): Amitriptyline metabolism: Relationship to polymorphic debrisoquine hydroxylation. Clin Pharmacol Ther 34: 516-520

Mellström B, Säwe J, Bertilsson L, Sjöqvist F (1986): Amitriptyline metabolism: Association with debrisoquin hydroxylation in non-smoker. Clin Pharmacol Ther 39: 369-371

Nakamura K, Goto F, Ray WA, McAllister CB, Jacqz E, Wilkinson GR, Branch RA (1985): Interethnic differences in genetic polymorphism of debrisoquin and mephenytoin hydroxylation between Japanese and Caucasian populations. Clin Pharmacol Ther 38:402-408

Nielsen KK, Brøsen K, Gram LF, The Danish University Antidepressant Group (1992): Steady-state plasma levels of clomipramine and its metabolites: Impact of the sparteine/debrisoquine oxidation polymorphism. Eur J Clin Pharmacol 43:405-411

Nies A, Robinson DS, Friedman MJ, Green R, Cooper TB, Ravaris CL, Ives JO (1977): Relationship between age and tricyclic antidepressants plasma levels. Am J Psychiatry 134:790-793
Nordin C, Swiers B, Benitez J, Bertilsson L (1985): Plasma concentrations of nortriptyline and its 10-hydroxy metabolite in depressed patients-relationship to the debrisoquine hydroxylation metabolic ratio. Br J Clin Pharmacol 19:832-835

Otani K, Nordin C, Bertilsson L (1987): No interaction of diazepam on amitriptyline disposition in depressed patients. Ther Drug Monit 9:120-122

Potter WZ, Calil HM, Suftin TA, Zavadil AP, Jusko WJ, Rapoport J, Goodwin FK (1982): Active metabolites of imipramine and desipramine in man. Clin Pharmacol Ther 31:393-401

Siest G, Antonio B, Fouurnel S, Magdalow I, Thomassin I (1987): The glucuronyltransferases: What progress can pharmacologists expect from molecular biology and cellular enzymology? Biochem Pharmacol 36:983-989

Skjelbo E, Brösen K, Hallas J, Gram LF (1991): The mephenytoin oxidation polymorphism is partially responsible for the N-demethylation of Imipramine. Clin Pharmacol Ther 49:18-23

Someya T, Shibasaki M, Noguchi T, Takahashi S, Inaba T (1992): Haloperidol metabolism in psychiatric patients: Importance of glucuronidation and carbonyl reduction. J Clin Psychopharmacol 12:169-174

Spina E, Birgersson C, von Bahr C, Ericsson Ö, Mellström B, Steiner E, Sjöqvist F (1984): Pheontypic consistency in hydroxylation of desmethylimipramine and debrisoquine in healthy subjects and in human liver microsomes. Clin Pharmacol Ther 36:677-682.

Spina E, Steiner E, Ericsson Ö, Sjöqvist F (1987): Hydroxylation of desmethylimipramine: Dependence on the debrisoquine hydroxylation phenotype. Clin Pharmacol Ther 41:314-319

Suftin TA, Perini GI, Molnar G, Jusko WJ (1988): Multipledose pharmacokinetics of imipramine and its major active and conjugated metabolites in depressed patients. J Clin Psychopharmacol 8:48-53

Träskman L, Bertilsson L, Åsberg M, Cronholm B, Mellström B, Neckers LM, Sjöqvist FE, Thoren P, Tybring G (1979): Plasma levels of chlorimipramine and its demethyl metabolites during treatment of depression. Clin Pharmacol Ther 26:600-610

Woolhouse NM, Adjepon-Yamoah KK, Mellström B, Hedman A, Bertilsson L, Sjöqvist F (1984): Nortriptyline and debrisoquine hydroxylations in Ghananian and Swedish subjects. Clin Pharmacol Ther 36:374-378

Yue QY, Svensson JO, Alm C, Sjöqvist F, Säwe J (1989): Interindividual and interethnic differences in the demethylation and glucuronidation of codeine. Br J Clin Pharmacol 28:629-637 